\title{
Low Voltage Ride Through Capability Enhancement of Grid Connected Large Scale Photovoltaic System
}

\author{
Gazi Md. Saeedul Islam ${ }^{1}$, Ahmed Al-Durra ${ }^{1}$, S.M.Muyeen ${ }^{1}$, and Junji Tamura ${ }^{2}$ \\ ${ }^{1}$ Electrical Engineering Department, The Petroleum Institute, P.O.Box 2533, Abu Dhabi, UAE \\ ${ }^{2}$ Department of Electrical and Electronic Engineering, Kitami Institute of Technology, Japan, 090-8507, Kitami, Japan \\ E-mail: gislam@pi.ac.ae
}

\begin{abstract}
Recently interest in photovoltaic (PV) power generation systems is increasing rapidly and the installation of large PV systems or large groups of PV systems that are interconnected with the utility grid is accelerating. To maintain the grid stability due to the huge penetration of photovoltaic power to the grid, much stricter grid codes are being imposed by the energy regulatory bodies. This paper discusses the detailed modeling and control strategies of a large scale grid connected photovoltaic system that can help to augment the low voltage ride thorough capability of DC based PV plant. It should be noted that grid side inverter plays an important role in low voltage ride through and therefore, overvoltage and undervoltage tripping of DC link of the grid tied inverter should be avoided, if possible. This study attempts to incorporate DC link over and under voltage protection in the control loop without increasing overall cost of protective device, which is another salient feature of this study. Furthermore, a comparative study with conventional inverter scheme is carried out. Different types of fault scenarios are analyzed to demonstrate the effectiveness of the overall control scheme, where recent grid code for distribution generation system is considered.
\end{abstract}

\section{INTRODUCTION}

In recent years, power generation from renewable energy sources has been increasing significantly due to the environmental concerns regarding global warming caused by fossil fuels. Green energy friendly policies from governments of different countries are also boosting this growth. Photovoltaic (PV) system is one of the major renewable energy conversion systems. Electricity generation from solar power has been growing rapidly over the last decade because it is the most readily available source of energy. Total installed capacity of solar power has increased over 10 times from 2003 to 2009 (from $1.8 \mathrm{GW}$ to $20.4 \mathrm{GW}$ ) [1]. Apart from small residential applications, grid connected multi megawatt class PV plants are being installed. Present statistics says that over $150 \mathrm{PV}$ parks exist with $10 \mathrm{MW}$ or more capacity [2]. Due to increasing penetration of PV power in recent years, German grid codes has recently adopted low voltage ride through (LVRT) requirement for PV plants connected to the high [3] and medium [4] voltage network to provide dynamic grid support. This means that PV plants must stay connected during a fault, because shutdown of a megawatt class PV plant may have adverse effect in power system operation. Figure 1 shows the limiting curve for type 2 plants (generating plants other than synchronous

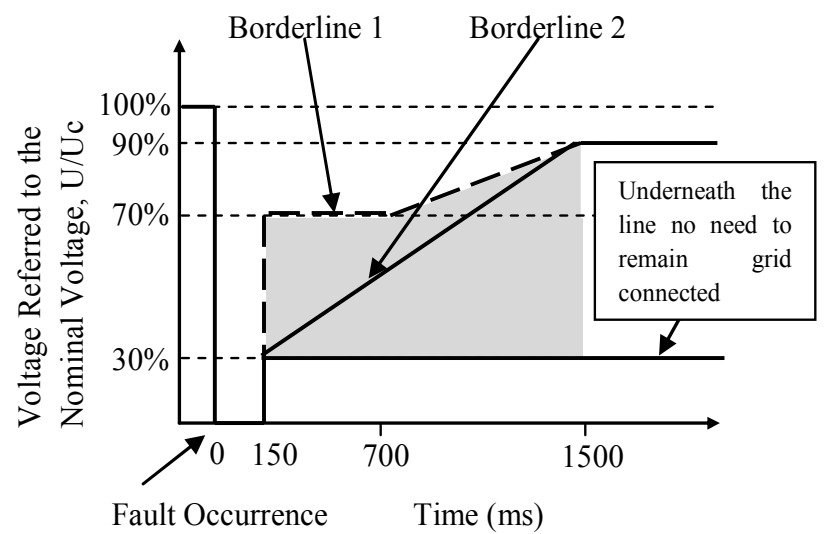

Fig. 1. Limiting curves of the voltage of a type-2 generator at the point of connection [4].

generators) connected to the medium voltage network [4]. A Plant must not disconnect from the network when the line voltage $(\mathrm{U})$ drops down to $0 \%$ of nominal voltage $\left(\mathrm{U}_{\mathrm{C}}\right)$ for a period less than or equal to $150 \mathrm{~ms}$ and should recover the $90 \%$ of the voltage from its pre-fault level within $1500 \mathrm{~ms}$ from the occurrence of the voltage dip. PV plants must comply with this from the beginning of 2011 [5]. Therefore, further analysis of low voltage ride through characteristics for grid connected MW class PV plant is necessary and focus should also be given on developing suitable control strategy that suits PV system.

In [6], LVRT characteristics analysis for high penetration $\mathrm{PV}$ power to the grid is reported where fault clearing time and location of the faults are focused. A current source inverter is emphasized in [7] for grid interfacing of PV plant. In both papers modeling of MW class PV plant, MPPT control scheme during grid fault, and coordinated control scheme between boost converter and grid-side inverter are not considered. In this study, the aforementioned issues are considered for enhancing the LVRT capability of grid connected MW class DC-bus based PV plants. A realistic MW class PV park model considering connection schemes of individual small modules, line length of DC cable between boost converter and DC link are taken into account while developing the coordinated control scheme.

During the fault condition, DC link voltage goes high due to the power imbalance between grid side and PV side. A dcchopper circuit is commonly used to protect the semiconductor devices [8]. In this paper a coordinated control 


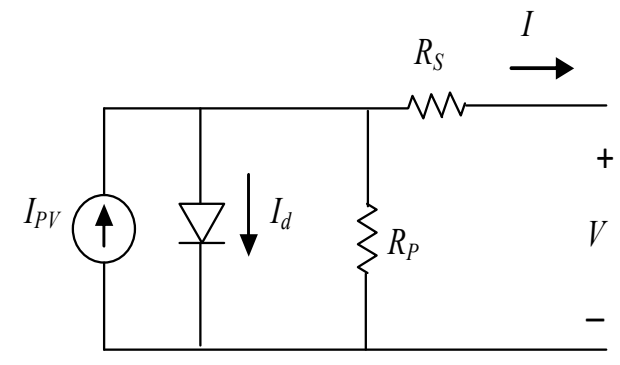

Fig. 2. Equivalent model of a PV module

scheme is proposed which helps to keep the DC link voltage rise within acceptable range without imposing additional system cost. The possibility of DC-link undervoltage tripping is reduced as well under the proposed control scheme. These are the other salient features of this study. Different types of symmetrical and unsymmetrical faults are analyzed by using laboratory standard power system simulator PSCAD/EMTDC [9] to verify the effectiveness of the proposed coordinated control strategy.

\section{PV SYSTEM}

A photovoltaic cell is a semiconductor diode which converts the incident sunlight into electrical energy. In practice, a PV module consists of a number of PV cells. Depending on the application, a single module or series parallel combination of multiple modules can be used.

\section{A. PV Module Modeling}

Figure 2 shows the equivalent circuit of a PV module which is composed of several PV cells. The output voltage and current relationship of a PV module can be expressed by [10]

$$
I=I_{P V}-I_{0}\left[\exp \left(\frac{q\left(V+I R_{S}\right)}{N_{S} a k T}\right)-1\right]-\frac{V+I R_{S}}{R_{P}}
$$

where $I_{P V}$ and $I_{0}$ are the photo-current and reverse saturation current of the PV module respectively. $N_{S}$ is the number of series connected cells, $q$ is the electron charge $\left(1.602176 \times 10^{-}\right.$ $\left.{ }^{19} \mathrm{C}\right), k$ is the Boltzmann constant $\left(1.3806503 \times 10^{-23} \mathrm{~J} / \mathrm{K}\right)$ and $a$ is the ideality factor of the diode. $R_{S}$ and $R_{P}$ are the equivalent series and parallel resistances of the module respectively. $I_{P V}$ is influenced by solar irradiation and temperature. This can be shown by [11]

$$
I_{P V}=\left(I_{P V, n}+K_{I} \Delta T\right) \frac{G}{G_{n}}
$$

where $I_{P V, n}$ is the photo-current of the module at nominal temperature and irradiation (usually $25^{\circ} \mathrm{C}$ and $1000 \mathrm{~W} / \mathrm{m}^{2}$ ), $\Delta T$ is the difference between actual and nominal temperature, $K_{I}$ is the short-circuit current temperature coefficient, $\mathrm{G}$ and $\mathrm{G}_{\mathrm{n}}$ are actual and nominal irradiation respectively. $I_{P V, n}$ and $I_{0}$ can be obtained by the following equations [10]

$$
\begin{aligned}
& I_{P V, n}=\frac{R_{P}+R_{S}}{R_{P}} I_{S C, n} \\
& I_{0}=\frac{I_{S C, n}+K_{I} \Delta T}{\exp \left(q\left(V_{O C, n}+K_{V} \Delta T\right) / N_{S} a k T\right)-1}
\end{aligned}
$$

where $I_{s c, n}$ and $V_{o c, n}$ are the short circuit current and open circuit voltage of the module at nominal condition respectively, $K_{V}$ is the open circuit voltage temperature coefficient.

\section{B. Aggregated Model}

For simulation purpose, it is necessary to model the system in aggregated fashion without hampering the behavior of the original system. For the equivalent model of a PV plant which consists of a number of PV modules, the following set of equations is developed:

$$
\begin{aligned}
& I=N_{P} I_{P V}-N_{P} I_{0}\left[\exp \left(\frac{q\left(V+I R S_{e q}\right)}{N_{M} N_{S} a k T}\right)-1\right]-\frac{V+I R_{S} S_{e q}}{R_{P e q}} \\
& I_{0}=\frac{N_{P} I_{S C, n}+K_{I} \Delta T}{\exp \left(q\left(N_{M} V_{O C, n}+K_{V} \Delta T\right) / N_{M} N_{S} a k T\right)-1}
\end{aligned}
$$

TABLE I

PARAMETERS FOR 2.5 MW PV PLANT

\begin{tabular}{|l|l|}
\hline Peak power & $2.5 \mathrm{MW}$ \\
\hline Voltage at maximum power & $973 \mathrm{~V}$ \\
\hline $\mathrm{N}_{\mathrm{S}}$ & 54 \\
\hline $\mathrm{N}_{\mathrm{M}}$ & 37 \\
\hline $\mathrm{N}_{\mathrm{P}}$ & 338 \\
\hline $\mathrm{R}_{\mathrm{Seq}}$ & $0.0242 \Omega$ \\
\hline $\mathrm{R}_{\text {Peq }}$ & $45.47 \Omega$ \\
\hline $\mathrm{a}$ & 1.3 \\
\hline
\end{tabular}

* For $25^{\circ} \mathrm{C}$ and $1000 \mathrm{~W} / \mathrm{m}^{2}$

TABLE II

LINE PARAMETERS

\begin{tabular}{|l|l|}
\hline Length of DC lines & $1 \mathrm{~km}$ \\
\hline $\mathrm{R}_{\mathrm{DC}}$ & $4.82 \times 10^{-4} \Omega$ \\
\hline $\mathrm{V}_{0}$ & $1.2 \mathrm{kV}$ \\
\hline Transformer voltage ratio $(\Delta-\mathrm{Y})$ & $0.763 \mathrm{kV} / 22 \mathrm{KV}$ \\
\hline $\mathrm{R}_{\text {grid }}$ (for each line) & $9.68 \Omega$ \\
\hline $\mathrm{L}_{\text {grid }}$ (for each line) & $0.18487 \mathrm{H}$ \\
\hline
\end{tabular}




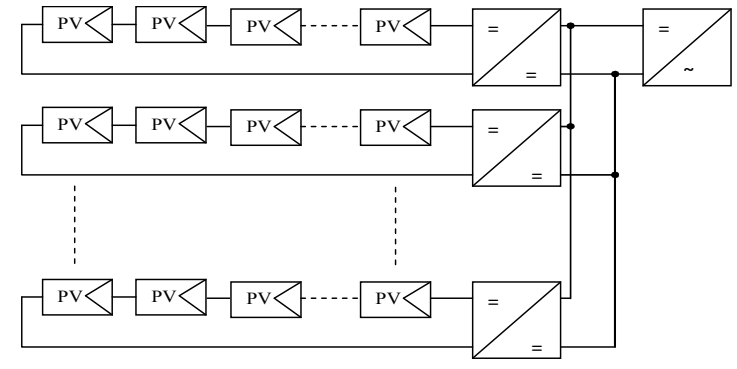

Fig. 3. Two stage PV System

where $N_{M}$ is the number of series connected modules in a string, $N_{p}$ is the number of strings connected in parallel, $R_{S e q}=\left(N_{M} \times R_{S}\right) / N_{P}$ and $R_{P e q}=\left(N_{M} \times R_{P}\right) / N_{P}$.

\section{PV Plant Topology}

Figure 3 shows the typical two stage grid connected PV plant with string topology. In this configuration, a number of solar panels are connected in series to form a string in order to get desired higher voltage. Each string is connected to a DC-DC (normally Boost) converter which is mainly used to extract maximum power from the PV string. A number of strings are then connected in parallel to a central inverter to obtain the required power. The function of the inverter is to transmit real power from PV park maintaining constant DC link voltage and to ensure reactive power demand of the grid as well. This topology reduces the losses incurred due to the mismatch between the strings and it is cost effective because of the reduction of number of inverters [12].

\section{MODELING AND CONTROL STRATEGIES OF THE PROPOSED SYSTEM}

The model system of a grid connected 5 MW (peak) PV plant is shown in Fig. 4. It is composed of two $2.5 \mathrm{MW} \mathrm{PV}$ units each connected to individual DC-DC boost converter. Figure 5 shows the characteristic curve of a $2.5 \mathrm{MW}$ unit. A DC link capacitor and a three phase voltage source inverter (VSI) are connected to maintain relatively constant DC voltage at the DC link and supply sinusoidal current to the

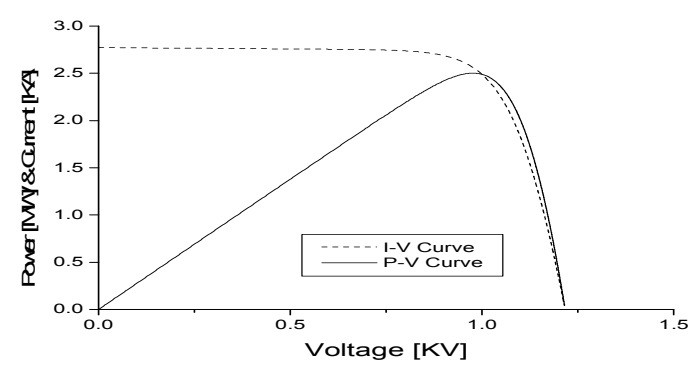

Fig. 5. I-V and P-V curve for 2.5 MW unit

grid. Finally, a $\Delta-\mathrm{Y}$ (Y grounded) transformer is used to integrate the system to the grid. In this paper, Kyocera KC200GT solar modules [13] are used and the parameters are found from [10]. A DC distribution system is modeled based on [14] and parameters are obtained from TOP SOLAR XZ$\mathrm{K}$ (AS) $1 \times 300 \mathrm{~mm}^{2}$ cable [15]. Double transmission line model is considered in this study. Different blocks of the model system are discussed in details in the following subsections. Parameters are given in table I and II.

\section{A. DC-DC Boost Converter Control}

The PV system is connected to the input side of a boost converter and its output side is connected to the DC link capacitor. Its gate signal is controlled to regulate the PV output voltage to a reference value so that maximum power can be extracted for a particular temperature and irradiation. There are number of maximum power point tracking (MPPT) techniques. Different MPPT techniques suit different applications and are discussed in details in [16]. In this paper fractional open-circuit voltage technique is used to obtain maximum power. Voltage of a PV module at maximum power point $\left(V_{M P P}\right)$ has nearly linear relationship with its open circuit voltage $\left(V_{O C}\right)$. The relationship can be written as

$$
V_{M P P}=K_{M P P} V_{O C}
$$

where $K_{M P P}$ is a proportionality constant. In order to avoid temporary disconnection from the network to get the open circuit voltage, an identical pilot module is used under the

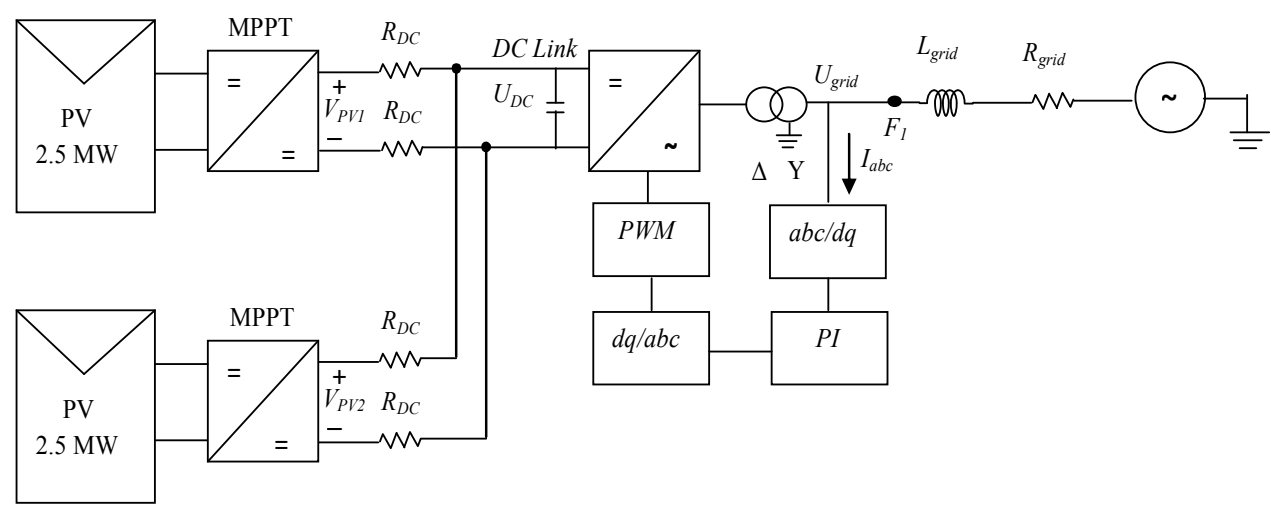

Fig. 4. Schematic diagram of the model system 


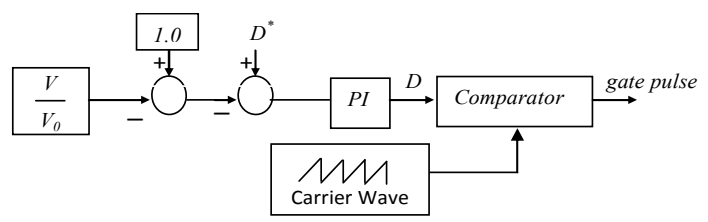

Fig. 6. Control block for boost converter

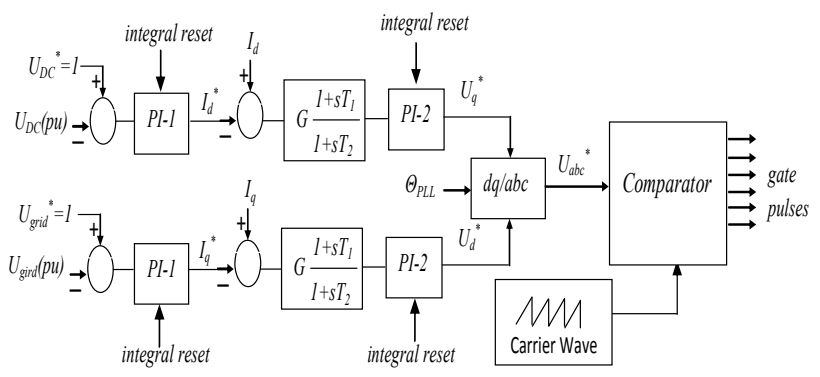

Fig. 7. Control block for voltage source inverter

same environmental condition [17]. The voltage then scales up to get the equivalent open circuit voltage of the string. Reference duty ratio is then found by the following equation

$$
D^{*}=1-\frac{N_{M} K_{M P P} V_{O C_{-}} \text {pilot }}{V_{0}}
$$

where $V_{O C \text { pilot }}$ is the open circuit voltage of the pilot module, $V_{0}$ is the output voltage of the boost converter. The control structure of the boost converter is shown in Fig. 6. For KC200GT solar module, value of $K_{M P P}$ is found to be equal to 0.8023 . This value is validated for different weather conditions $\left(25^{0} \mathrm{C}, 1000 \mathrm{~W} / \mathrm{m}^{2}\right.$ and $\left.47^{0} \mathrm{C}, 800 \mathrm{~W} / \mathrm{m}^{2}\right)$ from the datasheet of [13].

\section{B. Voltage Source Inverter Control}

The voltage source inverter is the most important component for integration of PV plant to the grid. In this paper widely used vector control technique is used for the three phase voltage source inverter control. The control scheme is shown in Fig. 7. A phase lock loop (PLL) is used to obtain the $\Theta_{P L L}$ which is used for abc to $\mathrm{dq} 0$ transformation of grid side current. The d-axis current $\left(I_{d}\right)$ is used to control the DC link voltage and the q-axis current $\left(I_{q}\right)$ ensures that a constant three phase rms voltage is delivered to the grid. The inner loop PI controller gives $U_{d}{ }^{*}$ and $U_{q}{ }^{*}$ which are then used for dq0 to abc transformation to get $U_{a b c}$. Finally, $U_{a b c}$ is sent to PWM signal generator to obtain the switching pulses for the voltage source inverter.

\section{DC Link Overvoltage Protection}

When a fault occurs, the inverter is unable to deliver power generated by the PV plant to the grid because of the drop in the grid voltage. The excess energy gives a sharp rise to the DC link voltage. It is, therefore, necessary to protect the DC

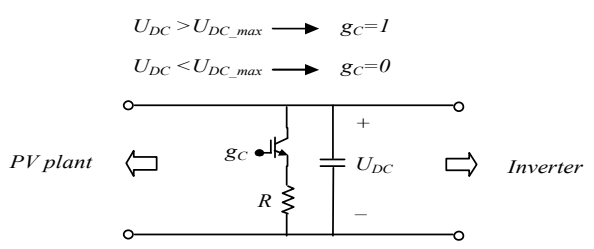

Fig. 8. Chopper circuit

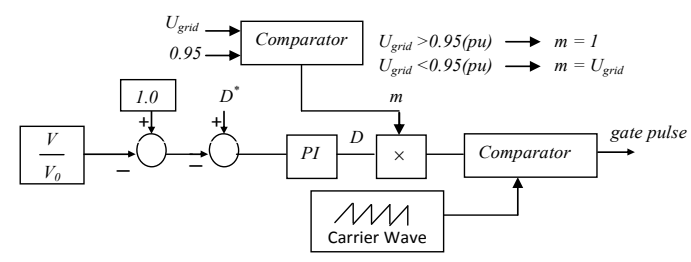

Fig. 9. Control block for DC link protection using MPPT

link from overvoltage. Two protection schemes are discussed in the following paragraphs.

\section{Conventional Protection Scheme}

In the first protection scheme a dc-chopper circuit is connected in parallel with the DC link capacitor [8]. The circuit and its corresponding control are shown in Fig. 8. The circuit consists of a resistance in series with an IGBT. During a fault, the DC link voltage becomes very high. This could damage the semiconductor devices. In this protection scheme, the gate pulse of the IGBT is triggered when the DC voltage goes higher than a certain threshold value. The access energy is then absorbed by the resistance of the chopper circuit. Thus, the chopper circuit protects the DC link voltage from going above a certain level. It is noted that conventional protection scheme cannot prevent undervoltage tripping.

\section{Proposed Protection Scheme}

Additional cost is involved while adopting dc-chopper circuit for over voltage protection of DC-link. Therefore, in the second protection scheme the control of the boost converter (MPPT control) is utilized for overvoltage protection (Fig. 9). In this protection scheme grid voltage is monitored and used to modify the duty ratio command signal when grid side voltage goes below a certain threshold value. Therefore, the controller sets the reference duty ratio to zero or reduces it suitably based on the severity of the grid fault. In this way, duty ratio can be used much precisely compare to the case when no protection is applied. The controller thus forces the PV module to send power towards the DC-link in a controlled way. Hence, DC link voltage rise can be minimized. On the otherhand, plant need to be shutdown if the DC link voltage becomes very low during grid disturbance. In order to prevent that, all the integral controller of the voltage source inverter is reset when the DC link voltage goes below a certain threshold value. Thus the proposed scheme can be implemented easily without incorporating substantial modification in the existing control strategy and additional circuit elements are no longer necessary. 


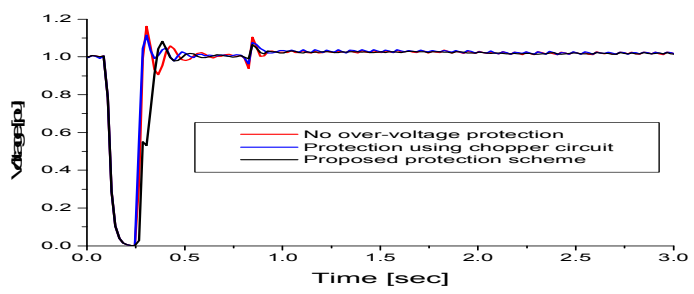

Fig. 10. Grid side voltage (3LG fault)

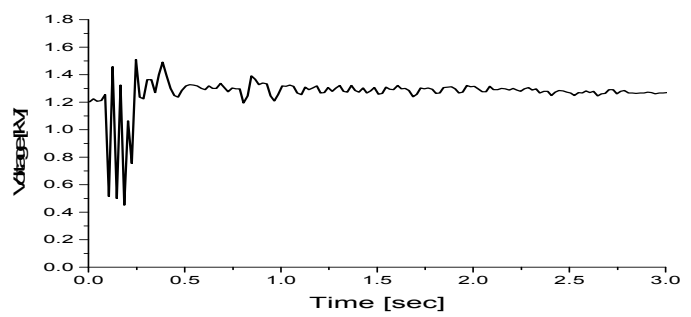

Fig. 11. DC link voltage with proposed protection scheme (3LG Fault)

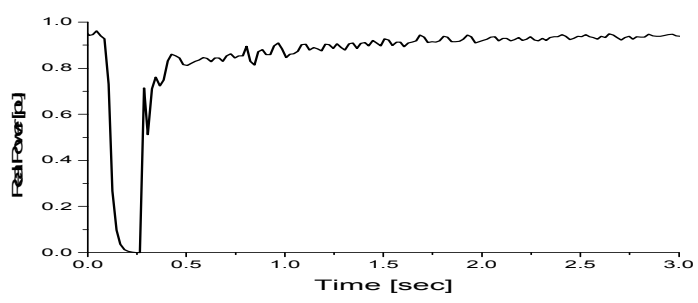

Fig. 12. Real power delivered to the grid for proposed protection scheme (3LG fault)

\section{SimULATION RESUlTS}

Simulations are performed considering a symmetrical 3LG (three-line-to-ground), 2LG and L-L faults at $F_{l}$ location shown in Fig. 4 using PSCAD/EMTDC [9]. Fault is considered in one of the double circuit transmission line. Simulation time step is $30 \mu$ s and simulation time is considered as $3 \mathrm{~s}$.

The fault is considered at $0.1 \mathrm{~s}$; the breakers of the transmission line opened at $0.25 \mathrm{~s}$ and reclosed at $0.8 \mathrm{~s}$. All the simulations are done for standard test condition (STC) $\left(1000 \mathrm{~W} / \mathrm{m}^{2}\right.$ and $\left.25^{\circ} \mathrm{C}\right)$ [18]. During steady state condition, DC link rated voltage is $1.2 \mathrm{kV}$. The terminal voltage without considering over voltage protection, conventional protection, and proposed protection are shown in Fig. 10. In all cases the voltage returns to the nominal voltage within $0.4 \mathrm{~s}$. Hence, the grid code mentioned in Sect. I can be met with the control strategy used in this paper.

For the proposed protection scheme, integral controllers of the voltage source inverter are reset for DC link voltage between $0.68>U_{D C}>0.5$ p.u. to prevent the under voltage. As can be seen from Fig. 11, the DC link voltage for 3LG

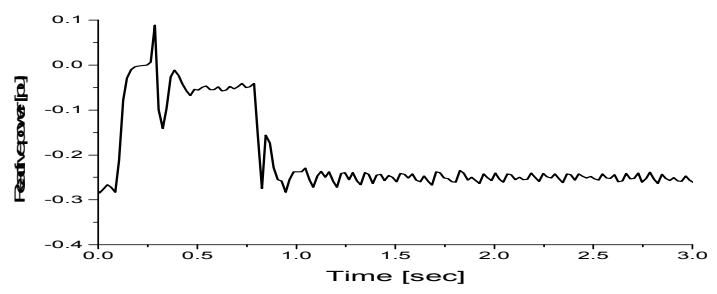

Fig. 13. Reactive power delivered to the grid for proposed protection scheme (3LG fault)

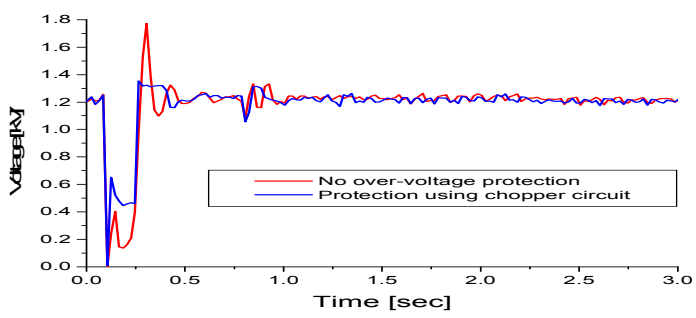

Fig. 14. DC link voltage (3LG fault)

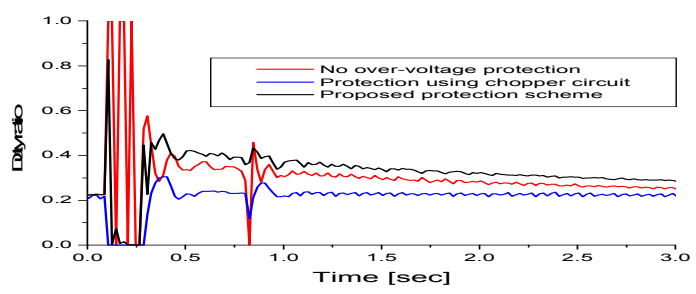

Fig. 15. Duty ratio of DC-DC converter (3LG fault)

fault remains within 0.4 pu. Overshoot is $125 \%$ of the nominal voltage. Real and reactive power delivered to the grid for the proposed scheme are also shown in Fig. 12 and 13 respectively.

DC link voltage for no over voltage protection and conventional protection scheme for $3 \mathrm{LG}$ fault is shown in Fig. 14. The voltage goes upto $1.8 \mathrm{kV}(150 \%$ of the nominal voltage) during the fault condition when the over voltage protection is not applied. This would lead to the tripping of the generation plant. In the conventional overvoltage protection control, $U_{D C_{-} \max }$ (shown in Fig. 8) is set to $1.32 \mathrm{kV}$ ( $110 \%$ of nominal voltage). Therefore, beyond this value the chopper circuit is activated and the energy is dissipated in the internal resistance of the circuit. From the Fig. 14, it is apparent that the DC link voltage overshoot for $3 \mathrm{LG}$ fault is slightly above $110 \%$. Hence, it is a very effective overvoltage protection method.

Comparison of duty ratio for no over voltage protection, protection scheme using chopper circuit, and proposed protection scheme are shown in Fig. 15. Duty ratio oscillates in case of no overvoltage protection as there is no control over the duty ratio during the fault condition. In case of the proposed over voltage protection control, threshold value for $U_{\text {grid }}$ (shown in Fig. 9) is set to $0.95 \mathrm{pu}$ of the nominal voltage. Below this voltage level, duty ratio of the boost 


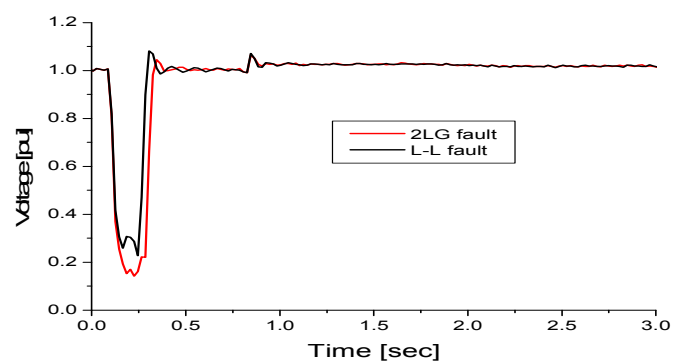

Fig. 16. Grid side voltage for proposed protection scheme (2LG \& L-L faults)

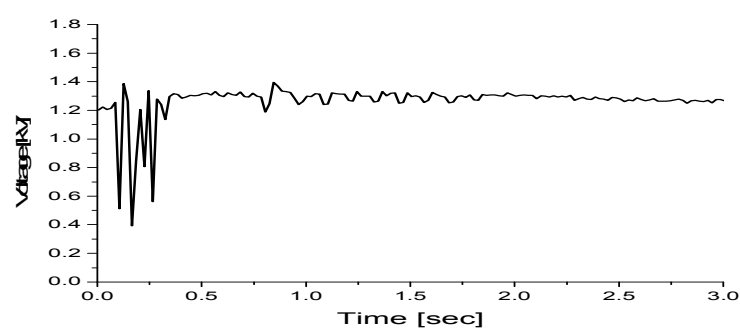

Fig. 17. DC link voltage for proposed protection scheme (2LG fault)

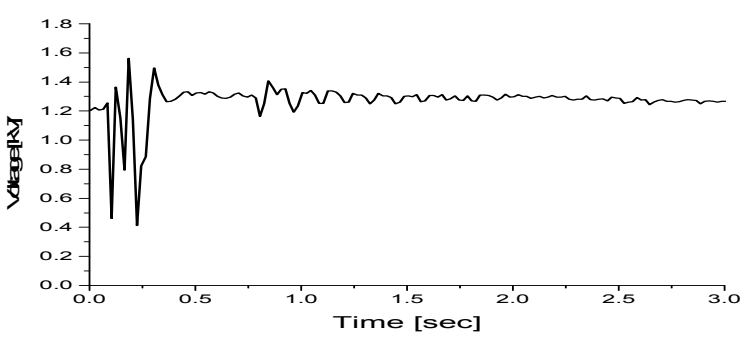

Fig. 18. DC link voltage for proposed protection scheme (L-L fault)

converter changes in accordance with the terminal voltage. The objective here is to operate the PV plant at lower power point and reduce the power flow from boost converter towards the voltage source inverter (VSI). Thus it reduces the power mismatch between the input and output side of the VSI. From Fig. 15, it is apparent that the duty ratio remains zero during the fault conditions for both protection schemes. Grid side voltage and DC link voltage for unsymmetrical faults like $2 \mathrm{LG}$ and $\mathrm{L}-\mathrm{L}$ faults using proposed protection scheme are also shown in Fig. 16, 17, and 18.

\section{CONCLUSION}

In this paper, detailed modeling and control strategies of a MW class DC-based PV plant have been presented. LVRT characteristics for different types of symmetrical and unsymmetrical faults have been analyzed. A DC link over voltage and undervoltage protection schemes have also been proposed and compared with the conventional scheme. It is found that under the coordinated control scheme DC link over voltage can be kept within acceptable range without incorporating additional cost. It is also found that DC-link undervoltage tripping condition can be avoided using the proposed scheme. Finally, it is concluded that the proposed coordinated control scheme can successfully augment the LVRT capability of MW class DC-based PV plant under various fault conditions as required by the recent grid code.

\section{REFERENCES}

[1] Trends in photovoltaic applications- Survey report of selected IEA countries between 1992 and 2009. [Online]. Available: http://www.ieapvps.org/

[2] Large-scale photovoltaic power plants ranking. [Online]. Available: http://www.pvresources.com/en/top50pv.php.

[3] "Transmission code 2007 - network and system rules of the German transmission system operators," Verband der Netzbetreiber (VDN), Aug. 2007.

[4] "Technical guideline - generating plants connected to the mediumvoltage network," Bundesverband der Energie- und Wasserwirtschaft,BDEW, Jun. 2008.

[5] E. Troester, "New German grid codes for connecting PV systems to the medium voltage power grid," $2^{\text {nd }}$ International Workshop on Concentrating Photovoltaic Power Plants: Optical Design, Production, Grid Connection, Darmstadt, Germany, Mar. 2009.

[6] N. H. Viet, and A. Yokoyama, "Impact of fault ride-through characteristics of high-penetration photovoltaic generation on transient stability," International Conference on Power System Technology, Dec. 2010 .

[7] C. Photong, C. Klumpner, and P. Wheeler, "A current source inverter with series connected AC capacitors for photovoltaic application with grid fault ride through capability," 35th Annual Conference of IEEE on Industrial Electronics (IECON), Nov. 2009

[8] R. Takahashi, J. Tamura, M. Futami, M. Kimura, and K. Idle, "A New Control Method for Wind Energy Conversion System using Double Fed Synchronous Generators," IEEJ Trans. Power and Energy, Vol. 126, No. 2, pp. 225-235, 2006.

[9] "PSCAD/EMTDC user's guide," Manitoba HVDC Research Center, 2005.

[10] M. G. Villalva, J. R. Gazoli, and E. R. Filho, "Comprehensive approach to modeling and simulation of photovoltaic arrays," IEEE Trans. Power Electron., Vol. 24, no. 5, pp. 1198-1208, May 2009.

[11] G. Vachtsevanos, and K. Kalaitzakis, "A Hybrid Photovoltaic Simulator for Utility Interactive Studies," IEEE Trans. Energy Conv., Vol. EC-2, no. 2, Jun. 1987.

[12] M. Brenna, R. Faranda, and S. Leva, "Dynamic analysis of a new network topology for high power grid connected PV systems," Power and Energy Society General Meeting, Minneapolis, Jul. 2010.

[13] Kyocera KC200GT- high efficiency multicrystal photovoltaic module datasheet. [Online]. Available: http://www.kyocera.com.sg/products/solar/pdf/kc200gt.pdf

[14] M. R. Starke, and L. Tolbert, "DC Distribution with Fuel Cells as Distributed Energy Resources," in Proc. Ph.D. Res. Electrical Engineering, Dec. 2009.

[15] Cables for photovoltaic solar installations. [Online]. Available: www.elesis.gr/php/download.php? file $=$ solar cables presentation.pdf

[16] T. Esram, and P. L. Chapman, "Comparison of photovoltaic array maximum power point tracking techniques," IEEE Trans. Energy Convers., vol. 22, no. 2, pp. 439-449, Jun. 2007.

[17] G.W. Hart, H. M. Branz, and C. H. Cox, "Experimental tests of openloop maximum-power-point tracking techniques," Solar Cells, vol. 13, pp. 185-195, Dec. 1984.

[18] W. Xiao, W. G. Dunford, and A. Capel, "A novel modeling method for photovoltaic cells," in Proc. IEEE 35th Anuu. Power Electron. Spec. Conf. (PESC), 2004, vol. 3, pp. 1950-1956. 